\title{
COMMENTARY
}

\section{Avoiding the humanitarian trap: The 'Nobelization' of food aid}

\author{
Lanika Sanders * \\ University at Buffalo
}

Submitted August 6, 2021 / Published online December 3, 2021

Citation: Sanders, L. (2021). Avoiding the humanitarian trap: The 'Nobelization'

of food aid. Journal of Agriculture, Food Systems, and Community Development, 11(1), 15-19. https://doi.org/10.5304/jafscd.2021.111.013

Copyright (C) 2021 by the Author. Published by the Lyson Center for Civic Agriculture and Food Systems. Open access under CC-BY license

\section{Abstract}

Despite the significant role that hunger relief has played in global emergency response efforts throughout much of the last century-notably showcased with the 2015 naming of 'Zero Hunger' as the second Sustainable Development Goal, and more recently when the World Food Program was awarded the 2020 Nobel Peace Prize_-significant hunger and malnutrition remain. Concerningly, past crises have demonstrated the potential for hunger relief efforts, particularly the provisioning of food aid, to undermine the ability of Global South countries and communities to recovery fully from shocks. This commentary takes a critical look at the role of food aid during extended crises and presents several thoughts for how aid agencies and Global North governments can continue to work toward Zero Hunger while simultaneously supporting Global South economies and cultures.

* Lanika Sanders, Research Affiliate, Food Systems and Healthy Communities Lab, University at Buffalo, Buffalo, New York; lanikacsanders@gmail.com

\section{Keywords}

Food Aid, Emergency Relief, COVID-19, Global South, Pandemic, Sustainable Development, Capacity-Building

\section{Introduction}

In October 2020, the Nobel Peace Prize was awarded to the World Food Programme (WFP) for its role in providing food aid to countries under duress due to COVID-19 and other emergencies (Nobel Prize Outreach AB, 2020a). In the words of David Beasley, executive director of WFP, the organization's recognition acts as "a reminder that food security, peace and stability go together" (Hookway, 2020, para. 23). As the prize has been awarded for food systems work only twice before-once in 1949 to Lord Boyd Orr, "Father of the Food and Agriculture Organization" (Nobel Prize Outreach AB, 2021a) and in 1970 to Norman Borlaug, "Father of the Green Revolution" (Nobel Prize Outreach AB, 2021b) WFP's award is instrumental in communicating 
the capacity of food systems work to enable healthy, resilient communities.

WFP was established in 1961 as an experiment in providing emergency hunger relief through the United Nations (UN), and has since helped forge a central place for food aid in humanitarian efforts (WFP, 2021b). The organization has prioritized the UN's second Sustainable Development Goal (SDG), 'Zero Hunger,' which was adopted in 2015 with the goal of eradicating hunger and malnutrition by 2030 (United Nations, n.d.). Emergency food provision is WFP's primary tool of action, and hunger eradication is used as a lever to achieve targets laid forth by other SDGs, such as ending poverty and acting against a rapidly changing climate. As a result of its efforts, WFP has become the largest humanitarian organization working to address hunger and food insecurity in the world (WFP, 2021a). In 2019, WFP assisted nearly 100 million people suffering from acute hunger and food insecurity in 88 countries, underscoring the invaluable role the organization plays in times of acute hunger and conflict.

\section{The Politics and Challenges of Food Aid as a Humanitarian Gesture}

Despite WFP's notable successes, significant hunger remains. An estimated 690 million people$8.9 \%$ of the world population-were undernourished in 2019, and with global hunger on the rise, ending hunger by 2030 becomes an ever more distant reality (Food and Agriculture Organization of the United Nations [FAO], International Fund for Agricultural Development [IFAD], UNICEF, WFP, \& World Health Organization [WHO], 2020). Examining the food sovereignty challenges of local communities, driven partly by the structural and systemic inequities characteristic of 'food apartheid,' offers an even more striking image of how distant the end of hunger remains, and how inadequate current international aid strategies have proven to be in meeting this ambitious goal (Bradley \& Galt, 2014).

Consider, for instance, the role of emergency rice provision in the decimation of Haiti's economy. To bolster the stagnant American farming economy of the 1980s, U.S. policymakers put pressure on Haiti to reduce tariffs, using the 1985
U.S. farm bill to flood Haiti's markets with subsidized U.S. rice in the name of food aid (Armand, 2019). Haiti was forced to halt subsidies for domestic rice production, leaving Haitian rice producers to compete with large foreign producers in what was essentially a losing battle. Local markets were destroyed, and farmers, who could no longer make a living producing rice, were thrust into urban areas searching for work (Matheson Miller, 2014). Slums grew quickly and chaotically, and their unstable construction and overcrowded conditions contributed to a massive loss of life when Haiti was hit by a magnitude 7.0 earthquake in 2010 (DesRoches et al., 2011).

Out of an abundance of benevolence, postearthquake humanitarian aid efforts inundated Haiti with even more food aid, trickling in for years after the event (Matheson Miller, 2014). Today, a full $80 \%$ of Haiti's rice is imported, and just recently Haiti's food insecurity was upgraded from 'alarming' to 'serious' on the Global Hunger Index (Cochrane et al., 2016; Concern Worldwide \& Welthungerhilfe, 2021). Further, nutritionally dense domestic grains, which have traditionally composed a significant portion of the Haitian diet, have been displaced by cheap foreign rice. This unbalancing of the traditional Haitian diet has contributed to the growing double burden of malnutrition seen among many Global South countries, characterized by undernutrition coexisting with overnutrition (Popkin et al., 2020).

The role that food aid plays in undermining local economies calls into question the function of such aid in extended crises. Although aid in the face of immediate food shortages is arguably essential, such as immediately after an earthquake, when does food aid become an imposition in the face of emergencies that drag on for months? This question is even more challenging when considering crises that require the creation of economic lags, the current COVID-19 pandemic providing one example. Preliminary data suggests that by the end of 2020, COVID-19 had increased the total number of undernourished people by between 83 and 132 million individuals (FAO et al., 2020). Certainly action must be taken to reduce such adversity during this crisis. That said, considering that the pandemic will 
likely continue for months, are aid agencies such as WFP doing a disservice to target countries by continuing to provide food aid?

Looking critically at the potential repercussions of food aid opens discourses about the role of humanitarian aid, both in general and of food aid in particular. Supporting, recognizing, and prioritizing global food issues, such as those pursued by WFP and other global organizations, are crucial in the advancement of worldwide health and equity. However, these measures must occur alongside the support, recognition, and prioritization of local food systems efforts-from food production to waste management - in villages, towns, and municipalities, especially those in Global South countries.

\section{Some Thoughts about Thinking Globally but Acting Locally to Secure Our Common Food Future}

Imperatively, international aid agencies should focus on providing hunger relief without undermining local food economies. By incorporating the lessons learned from past errors into present-day protocols, hunger relief tools can be altered to ensure the promotion of long-term food security in target populations. Three ideas for the way forward are laid out below.

1. Aid agencies should, to the extent possible, source food first from small farms local to the target area. In short-term situations where a lack of production is the main barrier to food security (for instance, during periods of extreme flooding or drought, leading to acute undernourishment), the agencies should source food from global markets, while working with local producers and municipalities to provide the planning and financial support necessary to wean localities off such aid as soon as possible. This approach recognizes that strengthening local-level food production is paramount to agricultural sustainability (a central target of SDG 2), but that uplifting all food system sectors is necessary to prevent local and global food aid production networks from engendering negative externalities. These include labor and food security inequities for women (Botreau \&
Cohen, 2019), addressed in SDG 10, 'Reduced Inequalities,' and SDG 5, 'Gender Equality,' facilitated by SDG 8, 'Decent Work and Economic Growth,' or the generation of unmanaged food waste (Cochrane et al., 2016), prevented via SDG 12, 'Responsible Consumption and Production.' Corresponding with its local food procurement policy, WFP itself has sourced a significant amount of "locally grown commodities" in recent years, procuring 33\% of its purchases locally in 2018 (WFP, 2019, p. 7). In the wake of significant economic detriment to small enterprises by COVID-19, WFP should prioritize an expansion of these activities.

2. If the barriers to food security are financial in nature, organizations should first provide monetary aid and capacity-building services aimed directly at the food system sector experiencing inefficiency. For instance, the installation of solar irrigation pumps in Bangladesh has allowed rural farming communities to halve their irrigation costs (Ahmed Mahbub, 2016), and in Guatemala, the establishment of e-commerce platforms and other technologies has allowed growers to streamline sales of surplus produce (De Ferrari Piazza et al., 2020). Investment in resilient infrastructure thus equates to investment in a community's ability to adapt and progress in the face of challenges, as outlined in SDG 9, 'Industries, Innovation and Infrastructure.' Along with direct investment into food system activities, investment into housing, transportation, and healthcare indirectly bolsters food security, providing a platform to boost physical and financial access to food.

3. As an alternative to provisioning communities with specific projects and foods, global organizations can use cash-based transfers to equip households with the financial capacity to meet their own needs. In the Somali region of Ethiopia, for instance, the FAO has provided unconditional cash transfers (UCTs) to approximately 4,500 pastoral households affected by drought (FAO, 2020a). The program has not only enabled the beneficiaries to purchase food and 
other necessary supplies as a replacement for lost agricultural yield, but also to invest in agricultural inputs that boost farm production. Similarly, aid organizations can provide vouchers that are redeemable for certain food-related goods and services, a strategy that has proven particularly useful in boosting food production and nutritional security. One example is the FAO's cash-for-seeds program in South Sudan, which provides vulnerable families each with 5,000 South Sudanese pounds (US\$30) to purchase seeds and other necessary agricultural inputs at local markets (FAO, 2020b). In addition to supporting local businesses and agricultural prosperity, this conditional cash transfer (CCT) program allows farmers autonomy to act upon traditional agricultural insight, enabling SDG 11, 'Sustainable Cities and Communities.' The use of CCTs and UCTs has been popularized by the 2019 Nobel Prize for Economics winners, Esther Duflo, Michael
Kreme, and Abhijit Banerjee, who argue that cash transfer programs are effective policy mechanisms to reduce poverty in global South countries (Banerjee et al., 2017; Nobel Prize Outreach AB, 2020b).

Through capacity-building activities, mindful food procurement, and household empowerment, the proposed solutions enlist alternative and intersectional methods of tackling emergency relief. By addressing food system challenges in tandem with the roots of these challenges, aid organizations hold the power to advance global outcomes toward eliminating poverty (SDG 1), ultimately reducing acute and long-term hardship.

\section{Acknowledgements}

I would like to thank Professor Emmanuel Frimpong Boamah for his invaluable encouragement and feedback on this work, and Professor Samina Raja for her review and support.

\section{References}

Ahmed Mahbub, M. (2016, March 29). Solar irrigation pumps: A new way of agriculture in Bangladesh. World Bank. https://blogs.worldbank.org/endpovertyinsouthasia/solar-irrigation-pumps-new-way-agriculture-bangladesh

Armand, J. (2019). Establishing economic independence in Haiti through public-private partnerships and foreign direct investments notes. Northwestern Journal of International Law \& Business, 40(3), 363-390. https:/ / heinonline.org/HOL/PrintRequest?handle=hein.journals/nwjilb40\&collection=journals\&div $=17 \&$ id $=371$ \&print $=$ section\&sction $=17$

Banerjee, A. V., Hanna, R., Kreindler, G. E., \& Olken, B. A. (2017). Debunking the stereotype of the lazy welfare recipient: Evidence from cash transfer programs. The World Bank Research Observer, 32(2), 155-184. https://doi.org/10.1093/wbro/lkx002

Botreau, H., \& Cohen, M. (2019). Gender inequalities and food insecurity. Oxfam International. https://reliefweb.int/sites/reliefweb.int/files/resources/bp-gender-inequalities-food-insecurity-150719-en.pdf

Bradley, K., \& Galt, R. E. (2014). Practicing food justice at Dig Deep Farms \& Produce, East Bay Area, California: Selfdetermination as a guiding value and intersections with foodie logics. Local Environment, 19(2), 172-186. https://doi.org/10.1080/13549839.2013.790350

Cochrane, N., Childs, N., \& Rosen, S. (2016). Haiti's U.S. rice imports. U.S. Department of Agriculture, Economic Research Service. https://www.ers.usda.gov/webdocs/outlooks/39144/56601 rcs-16a-01.pdf.v=7367.1

Concern Worldwide \& Welthungerhilfe. (2021). 2020 Global Hunger Index. https://www.globalhungerindex.org/ranking.html

De Ferrari Piazza, C., Perego, V., \& Kennedy Freeman, K. (2020). Leveraging technology to support Guatemala's food chain during COVID-19. World Bank. https://blogs.worldbank.org/latinamerica/leveraging-technology-support-guatemalas-food-chain-during-covid-19

DesRoches, R., Comerio, M., Eberhard, M., Mooney, W., \& Rix, G. J. (2011). Overview of the 2010 Haiti earthquake. Earthquake Spectra, 27(Suppl. 1), 1-21. https://doi.org/10.1193/1.3630129

Food and Agriculture Organization of the United Nations [FAO]. (2020a). Drought-affected households in Ethiopia benefit from FAO cash-transfer project. http://www.fao.org/emergencies/fao-in-action/stories/stories-detail/en/c/1259914/ 
FAO. (2020b). South Sudan: Cash for seeds brings new hope to Santa and 12,000 vulnerable farmers in Magwi. http://www.fao.org/emergencies/fao-in-action/stories/stories-detail/en/c/1304850/

FAO, International Fund for Agricultural Development [IFAD], UNICEF, WFP, \& World Health Organization [WHO]. (2020). The state of food security and nutrition in the world 2020. https://www.wfp.org/publications/state-food-security-and-nutrition-world-sofi-report-2020

Hookway, J. (2020, October 9). Nobel Peace Prize is awarded to the World Food Programme. The Wall Street Journal. https://www.wsj.com/articles/nobel-peace-prize-is-awarded-to-the-world-food-programme-11602234412

Matheson Miller, M. (Director-Producer). (2014). Poverty, Inc. [Film]. Acton Institute PovertyCure, Action Media, \& ColdWater Media.

Nobel Prize Outreach AB. (2020a). The Nobel Peace Prize 2020. https://www.nobelprize.org/prizes/peace/2020/summary/

Nobel Prize Outreach AB. (2020b). The Prize in Economic Sciences 2019 [Press release]. https://www.nobelprize.org/prizes/economic-sciences/2019/press-release/

Nobel Prize Outreach AB. (2021a). Lord Boyd Orr - Facts. https://www.nobelprize.org/prizes/peace/1949/orr/facts/

Nobel Prize Outreach AB. (2021b). Norman Borlang - Facts. https://www.nobelprize.org/prizes/peace/1970/borlaug/facts/

Popkin, B. M., Corvalan, C., \& Grummer-Strawn, L. M. (2020). Dynamics of the double burden of malnutrition and the changing nutrition reality. Lancet, 395(10217), 65-74. https://doi.org/10.1016/S0140-6736(19)32497-3

United Nations. (n.d). Goal 2: Zero hunger. Retrieved November 23, 2021, from https://www.un.org/sustainabledevelopment/hunger/

World Food Programme [WFP]. (2019). Policy on local food procurement: Second informal consultation. https://docs.wfp.org/api/documents/WFP-0000108272/download/

WFP. (2021a). 12 things you did not know about WFP [Factsheet]. https://www.wfp.org/publications/12-things-you-did-not-know-about-wfp

WFP. (2021b). History. Retrieved August 4, 2021, from https://www.wfp.org/history 